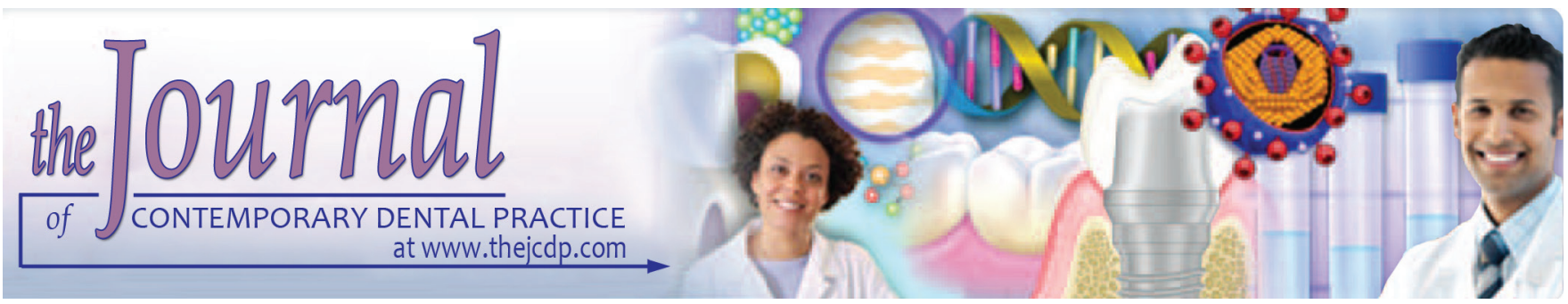

\title{
Evaluation and Comparison between Formocresol and Sodium Hypochlorite as Pulpotomy Medicament: A Randomized Study
}

${ }^{1}$ Shikhar P Chauhan, ${ }^{2}$ Mukesh Gupta, ${ }^{3}$ Hina Ahmed, ${ }^{4}$ Ravish Tongya, ${ }^{5}$ Dheeraj Sharma, ${ }^{6}$ Bhanu Chugh

\begin{abstract}
Introduction: Pulpotomy is the most common treatment to preserve vitality of cariously exposed molars. Various pulpotomy medicaments used should be antimicrobial, should help in healing without damaging surrounding tissue, and should not affect eruption of permanent teeth. Thus, this study was conducted to evaluate and compare the clinical and radiographic outcomes of formocresol (FC) and sodium hypochlorite ( $\mathrm{NaOCl})$ in primary molars. The aim of this randomized study was to compare the clinical and radiographic success rate of FC and $5 \% \mathrm{NaOCl}$ as a pulpotomy medicament in primary molars.
\end{abstract}

Materials and methods: Forty children aged 4 to 9 years with primary carious molar were selected and randomly assigned into two groups: $\mathrm{FC}$ and $\mathrm{NaOCl}$. Pulpotomy procedure was then performed followed by restoration with stainless steel crowns. Clinical and radiographic evaluation was done at an interval of 3 to 6 months.

Results: Clinical success rate at 3 and 6 months was $100 \%$ for both groups. Radiographic success rate for FC was $95 \%$ at 3 months and $90 \%$ at 6 months, whereas for $\mathrm{NaOCl}$, it was $90 \%$ at 3 months and $85 \%$ at 6 months.

\footnotetext{
${ }^{1}$ Department of Pediatric Dentistry, Index Institute of Dental Sciences, Indore, Madhya Pradesh, India

${ }^{2}$ Department of Orthodontics \& Dentofacial Orthopaedics, Index Institute of Dental Sciences, Indore, Madhya Pradesh, India

${ }^{3}$ Department of Conservative Dentistry \& Endodontics, College of Dental Science \& Hospital, Indore, Madhya Pradesh, India

${ }^{4}$ Department of Prosthodontics, Crown \& Bridge and Implantology Index Institute of Dental Sciences, Indore, Madhya Pradesh India

${ }^{5,6}$ Department of Oral and Maxillofacial Pathology, Index Institute of Dental Sciences, Indore, Madhya Pradesh, India

Corresponding Author: Shikhar P Chauhan, Department of Pediatric Dentistry, Index Institute of Dental Sciences, Indore Madhya Pradesh, India, Phone: +919425052374, e-mail: drshikharpratap@gmail.com
}

Conclusion: Based on this study, result of $5 \% \mathrm{NaOCl}$ and $\mathrm{FC}$ showed no significant difference in their success rate. Hence, $\mathrm{NaOCl}$ can be used as pulpotomy medicament; however, further clinical trials with long follow-up period are required.

Clinical significance: Sodium hypochlorite is a potential clinical substitute of FC for vital pulpotomy treatment in primary teeth because of its exceptional biological compatibility and to evade carcinogenic effect of FC.

Keywords: Formocresol, Primary molars, Pulpotomy, Sodium hypochlorite.

How to cite this article: Chauhan SP, Gupta M, Ahmed H, Tongya R, Sharma D, Chugh B. Evaluation and Comparison between Formocresol and Sodium Hypochlorite as Pulpotomy Medicament: A Randomized Study. J Contemp Dent Pract 2017;18(11):1029-1033.

\section{Source of support: Nil}

Conflict of interest: None

\section{INTRODUCTION}

Preservation of vitality of primary tooth whose pulp has been endangered by caries or trauma is a challenging treatment. Pulpotomy is one of the most common procedures used in pediatric dentistry. Pulpotomy is defined as "the surgical removal of the coronal portion of a vital pulp as a means of preserving the vitality of the remaining radicular portion." ${ }^{1}$ The objective is to maintain the primary teeth until permanent teeth erupt. Various materials have been used as pulpotomy medicaments which include FC, ferric sulfate, glutaraldehyde, laser, and mineral trioxide aggregate. Pulpotomy medicaments have been classified as devitalizing agent, preservative, and regenerative. ${ }^{2}$ Formocresol was introduced by Buckley in the year $1904 .^{2}$ Formocresol is a devitalizing agent, also called as mummifying agent. Despite its popularity, it was classified as carcinogenic for humans 


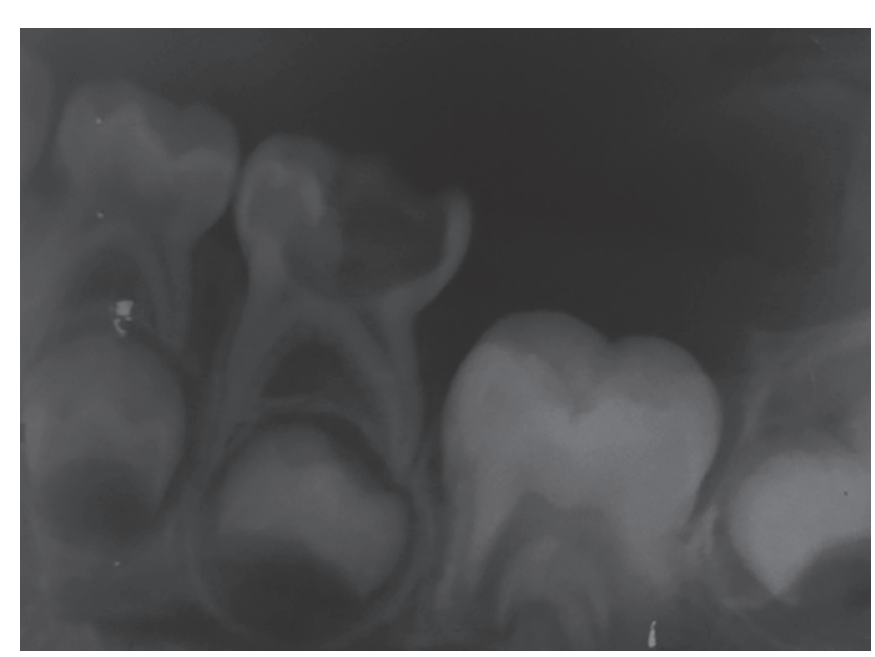

Fig. 1: Preoperative intraoral radiograph with respect to 85

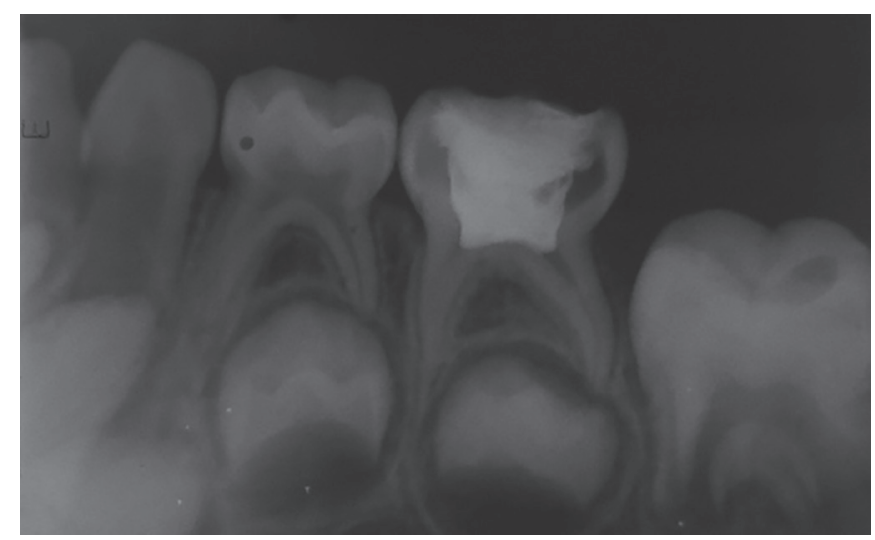

Fig. 3: Pulp chamber filled with ZOE after fixation with FC with respect to 85

in June 2004 by the International Agency for Research on Cancer. ${ }^{3}$

These findings have led researchers to find an alternative to FC. Sodium hypochlorite can be an alternative to FC. It is one of the best irrigants used for decades in endodontics, and it has gained its popularity for being antimicrobial agent. At $6 \%$ concentration, it kills almost all microorganisms or completely removes the biofilm from the root canals which chlorhexidine alone cannot do. ${ }^{4}$ Histological studies conducted by Hafez et $\mathrm{al}^{5}$ reported its use as a hemostatic agent in pulp therapy.

The purpose of this study was to evaluate and compare $5 \% \mathrm{NaOCl}$ with $\mathrm{FC}$ as a pulpotomy agent in primary molar.

\section{MATERIALS AND METHODS}

This randomized clinical trial was approved by the Institutional Ethical Committee. The participants selected for this study were healthy children aged between 4 and 9 years, 22 males and 18 females (Table 1). Teeth selected were primary molars which met following inclusion criteria:

- Exposure of pulp during caries excavation

- No signs of pulpal infection, i.e., mobility, sinus/fistula

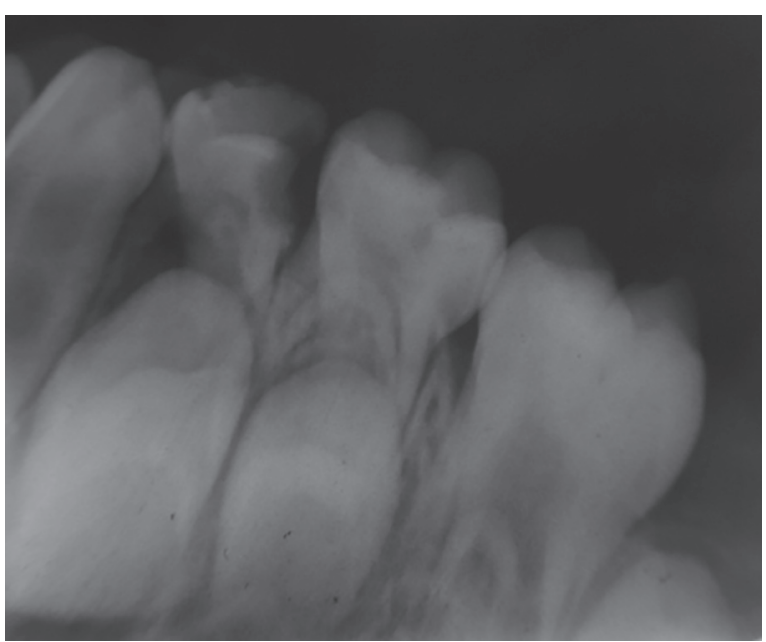

Fig. 2: Preoperative intraoral radiograph with respect to 64

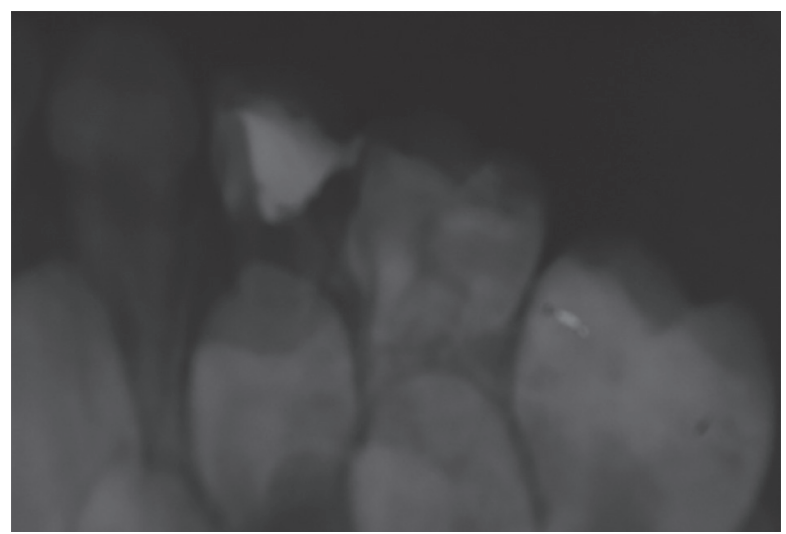

Fig. 4: Pulp chamber filled with $\mathrm{ZOE}$ after fixation with $\mathrm{NaOCl}$ with respect to 64

- No pulpal necrosis

- Hemostasis achieved after compression with a sterile cotton pellet

- The absence of radiographic pathology, such as furcal abscess and widening of periodontal ligament (PDL)

Periapical radiographs were taken with size 0 ultraspeed dental film (Eastman Kodak Co.) A total of 40 children were randomly allocated to one of the groups: FC (control group) (Figs 1 and 2) or $5 \% \mathrm{NaOCl}$ (experimental group) as listed in Table 2. Local anesthesia was administered; the selected teeth were isolated with a rubber dam. Caries was excavated using a sterile low-speed bur; coronal access was obtained. A sterile no. 6 carbide round bur was used for coronal pulp amputation, and hemostasis was achieved by a water-moistened cotton pellet. After obtaining hemostasis, pulpotomy medicament was placed in both groups with the help of cotton pellet: Group I-FC for 5 minutes $(n=20)$ and group II-5\% NaOCl for 30 seconds $(n=20)$. Cotton pellet was removed and cavity was rinsed with saline. In both groups, a layer of $2 \mathrm{~mm}$ zinc oxide eugenol (ZOE) was placed over the amputated pulp (Figs 3 and 4 ) and tooth was restored with miracle mix cement followed by placement of stainless steel 


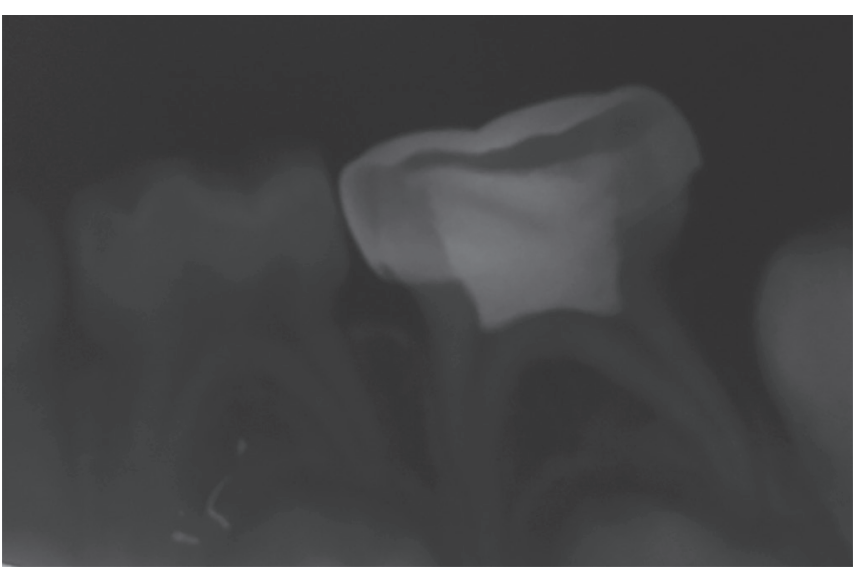

Fig. 5: Postoperative X-ray with stainless steel crown with respect to 85

Table 1: Patient demographic data

\begin{tabular}{ll}
\hline Mean age & $5.9(4-9$ years $)$ \\
Male (\%) & $22(55)$ \\
Female (\%) & $18(45)$ \\
\hline Total & 40 \\
\hline
\end{tabular}

crown (Figs 5 and 6). Patients were recalled after 3 and 6 months for clinical and radiographic evaluation.

\section{Clinical and Radiographic Evaluation}

Clinical success was based on the absence of following sign and symptoms, pain, mobility, and tender on percussion, sinus, or fistula. The criteria for radiographic success were met in the absence of internal and external root resorption, furcal abscess, and widening of PDL.

\section{Statistical Analysis}

Formocresol and $\mathrm{NaOCl}$ groups were analyzed separately. Both groups showed $100 \%$ clinical success rate. The radiographic data collected were compiled, tabulated, analyzed, and subjected to statistical tests. Analysis was done using Statistical Package for the Social Sciences. Wilcoxon's signed-rank test with significance level $p<0.05$ was used.

\section{RESULTS}

Forty primary molars in 40 children were randomly divided into two groups: $\mathrm{FC}(\mathrm{n}=20)$ and $\mathrm{NaOCl}(\mathrm{n}$ $=20$ ). After 3 and 6 months, out of 40 patients treated with pulpotomy, all 40 were available for the evaluation (Table 2). The clinical success rate for $\mathrm{FC}$ and $\mathrm{NaOCl}$ was $100 \%$ at 3 and 6 months. The absence of pain, mobility, sinus, or fistula led to the conclusion of $100 \%$ clinical success (Table 3). At 3 months radiographic evaluation, pathological changes in the development of furcal radiolucency, internal resorption, or excessive external root

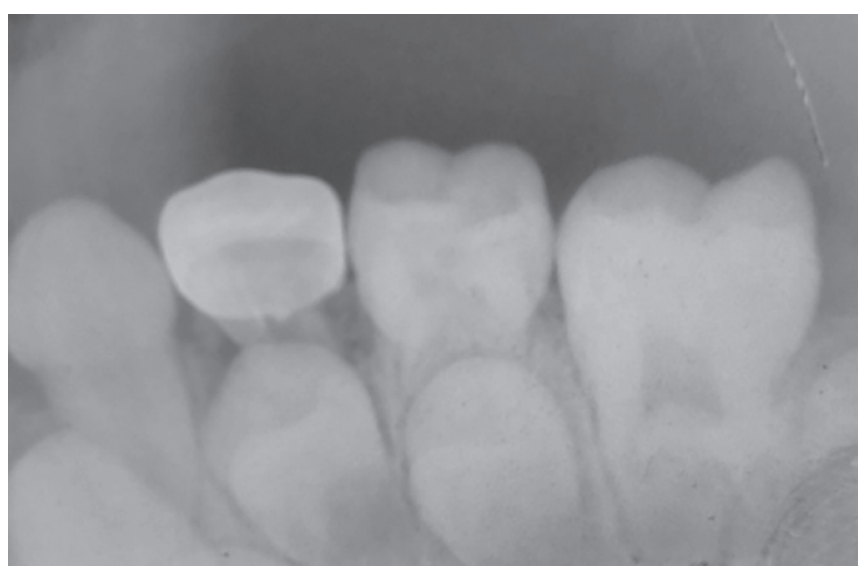

Fig. 6: Postoperative X-ray with stainless steel crown with respect to 64

Table 2: Distribution of primary molars in 3 and 6 months

\begin{tabular}{lllll}
\hline & 3 months & 6 months & \\
\hline FC & First molar & Second molar & First molar & Second molar \\
& 10 & 10 & 10 & 10 \\
NaOCl & First molar & Second molar & First molar & Second molar \\
& 10 & 10 & 10 & 10 \\
\hline Total & $\mathrm{n}=40$ & & $\mathrm{n}=40$ & \\
\hline
\end{tabular}

resorption were seen in 5\% $(1 / 20)$ of teeth treated with FC and $10 \%(2 / 20)$ of teeth treated with $\mathrm{NaOCl}(\mathrm{p}>0.05)$. At 3 months evaluation, one tooth from FC was assessed as radiographic failure (bifurcation radiolucencies). At the same time, two teeth from $\mathrm{NaOCl}$ were considered as failure (two teeth had internal resorption). The overall radiographic success rate at 3 months for FC group was $95 \%$ and $\mathrm{NaOCl}$ was $90 \%$ (Table 4 ).

At 6 months follow-up, radiographic changes as furcal radiolucency in one case and external root resorption in another case were seen (total two teeth) out of 20 samples, indicative of radiographic failure. This failure rate was $10 \%(2 / 20)$ of teeth treated with FC group. At the same time, three teeth from $\mathrm{NaOCl}$ were considered a failure (two teeth had internal resorption and one had widening of PDL). Hence, the failure rate was $15 \%$ $(3 / 20)$ in the $\mathrm{NaOCl}$ group (Table 4). There was no significant difference in radiographic outcome. The overall

Table 3: Comparison of $\mathrm{FC}$ and $\mathrm{NaOCl}$ clinical treatment outcome in 3 and 6 months

\begin{tabular}{lll}
\hline & $\begin{array}{l}\text { At 3 months } \\
n(\%)\end{array}$ & $\begin{array}{l}\text { At } 6 \text { months } \\
n(\%)\end{array}$ \\
\hline $\begin{array}{ll}\text { Groups I } \\
\text { Success }\end{array}$ & 20 & 20 \\
Failure & - & - \\
Group II & & \\
$\begin{array}{l}\text { Success } \\
\text { Failure }\end{array}$ & 20 & 20 \\
\hline p-value & - & - \\
\hline
\end{tabular}

"Wilcoxon's signed-rank test; NS: $p>0.05$, nonsignificant 
Table 4: Comparison of $\mathrm{FC}$ and $\mathrm{NaOCl}$ radiographic treatment outcome in 3 and 6 months

\begin{tabular}{lll}
\hline Groups & $\begin{array}{l}\text { At 3 months } \\
n(\%)\end{array}$ & $\begin{array}{l}\text { At } 6 \text { months } \\
n(\%)\end{array}$ \\
\hline Group I & & \\
Success & $19(95)$ & $18(90)$ \\
FFR & $1(5)$ & $1(5)$ \\
FIR & - & - \\
FER & - & $1(5)$ \\
FPDL & - & - \\
Group II & & \\
Success & $18(90)$ & $17(85)$ \\
FPR & - & - \\
FIR & $2(10)$ & $2(10)$ \\
FER & - & - \\
FPDL & - & $1(5)$ \\
p-value & $0.586^{\text {NS }}$ & $0.348^{\text {NS }}$ \\
\hline
\end{tabular}

FFR: Failure due to furcal radiolucency; FIR: Failure due to internal resorption; FER: Failure due to external root resorption; FPDL: Failure due to periodontal ligament widening; "Wilcoxon's signedrank test; NS: $p>0.05$, nonsignificant

radiographic success rate at 3 months for $\mathrm{FC}$ group was $95 \%$ and $\mathrm{NaOCl}$ was $90 \%$ and at 6 months $90 \%$ for $\mathrm{FC}$ group and $85 \%$ for $\mathrm{NaOCl}$.

\section{DISCUSSION}

Dental caries is infectious and multiple factors are involved for the initiation and progression of the disease in human. ${ }^{2}$ The pulp of a tooth can be exposed due to several causes, including dental caries, trauma, and during cavity preparation. Caries penetration of the pulp can cause bacteria invasion of the pulp, resulting in pulpal inflammation. The goal of vital pulp therapy is to treat reversible pulpal injury and maintain pulp vitality.

This randomized clinical trial compares the clinical and radiographic success rate of $\mathrm{FC}$ and $5 \% \mathrm{NaOCl}$ as a pulpotomy medicament in primary molars. The clinical success rate at 3 and 6 months was $100 \%$ for both groups. Radiographic success rate for FC was $95 \%$ at 3 months and $90 \%$ at 6 months, whereas for $\mathrm{NaOCl}$ it was $90 \%$ at 3 months and $85 \%$ at 6 months. Our results are similar to those of Vargas et $\mathrm{al}^{6}$ and they compared the effectiveness of $5 \% \mathrm{NaOCl}$ with that of ferric sulfate $\left(\mathrm{FeSO}_{4}\right)$ as a pulpotomy medicament in decayed primary molars. At 6 months, 100\% clinical success was found in both $\mathrm{FeSO}_{4}$ and $\mathrm{NaOCl}$ groups. Radiographic success for $\mathrm{FeSO}_{4}$ was $68 \%$. The $\mathrm{NaOCl}$ group showed $91 \%$ radiographic success. At 12 months, $\mathrm{FeSO}_{4}$ had 85\% clinical success and $62 \%$ radiographic success. $\mathrm{NaOCl}$ had $100 \%$ clinical success and 79\% radiographic success. Vostatek et $\mathrm{al}^{7}$ evaluated the clinical/radiographic success over 21 months of $5 \% \mathrm{NaOCl}$ as the medicament in primary molar pulpotomies. The $\mathrm{NaOCl}$ pulpotomies had a $95 \%$ clinical and $82 \%$ overall radiographic success rate.

Pulpotomy is one of the simple and commonly used treatments in the management of extensive caries in primary molars. Formocresol remains the "gold standard" for therapeutic pulpotomy in human primary teeth at a 1:5 dilution. Formocresol contains 19\% formaldehyde, $35 \%$ cresol in a vehicle of $15 \%$ glycerine and $31 \%$ water (Buckley's FC). ${ }^{8}$ The active ingredients of FC are formaldehyde and cresol. The first clinical success of FC was reported by Sweet $^{8}$ in the 1920 s who introduced a five appointment pulpotomy procedure using arsenic followed by FC as the devitalizing agent. Redig ${ }^{9}$ reported good success rate with 5-minute single visit pulpotomy in human teeth, after which the 5-minute treatment with FC has remained, the standard against which all new modalities are compared. Doyle et $\mathrm{al}^{10}$ compared the FC pulpotomy technique with the calcium hydroxide technique in primary canines and found the FC technique to be $95 \%$ clinically successful at the end of 1 year.

Question regarding carcinogenicity and mutagenicity is raised by various researchers. Meyers et $\mathrm{al}^{11}$ reported that 14C-labeled formaldehyde used in pulpotomy of primates has been found in PDL, bone, dentin, and urine. Small amounts of labeled formaldehyde were detected in liver, kidney, lungs, skeletal muscle, and cerebrospinal fluid within minutes of the medicament being placed at the pulpotomy site. These findings were confirmed by Pashley et al. ${ }^{12}$ However, Ranly et al calculated that over 3,000 pulpotomies would have to be performed in the same individual at the same time for FC to reach the toxin levels systemically. ${ }^{13}$

Sodium hypochlorite is also called as Dakin's solution. It was first used in the First World War as an antiseptic agent to clean wound. ${ }^{14}$ Grossman used 0.5 to $5.25 \%$ of $\mathrm{NaOCl}$ for root canal irrigations in the year 1961; since then, it has become a very popular medicament for such treatment in both the primary and permanent dentition. ${ }^{14}$

Hafez et $\mathrm{al}^{5}$ have performed two histological studies and reported $\mathrm{NaOCl}$ to be biologically compatible with exposed pulp tissue when used as a hemostatic agent in direct pulp capping. Rosenfeld et al demonstrated that using $5 \% \mathrm{NaOCl}$ had superficial effects on pulpal tissue, and its effects on deeper tissues were minimal. ${ }^{15}$

The radiographic success rate of $\mathrm{NaOCl}$ in the present study is similar to that observed in a number of previous studies. ${ }^{7,16}$ The primary cause of radiographic failure in the present study in the $\mathrm{NaOCl}$ group was internal root resorption, which was seen in three cases, which could be explained by the concentration used or the ZOE base. Hemostasis is a critical factor for clinical success of pulpotomies and is best achieved with $\mathrm{NaOCl}$. 
Thus, $\mathrm{NaOCl}$ has been found to have promising results as a pulpotomy agent in primary teeth with results comparable to the agent of choice for maintaining vital pulp tissue, i.e., calcium hydroxide (the associated internal resorption being the major problem with calcium hydroxide). Coupled with the easy availability of $\mathrm{NaOCl}$ in each and every clinical scenario, it can be stated that for preservation pulpotomies, $\mathrm{NaOCl}$ is one of the best materials available at easy disposal to every dentist.

\section{CONCLUSION}

The $5 \% \mathrm{NaOCl}$ and $\mathrm{FC}$ showed no significant difference in their success rate. Hence, $\mathrm{NaOCl}$ can be used as pulpotomy medicaments; nonetheless, further clinical trials with long follow-up period are required.

\section{REFERENCES}

1. Ingle JI, Bakland LK, Baumgartner JC. Ingle's endodontics. 6th ed. Hamilton: BC Decker Inc.; 2008.

2. Ranly DM. Pulpotomy therapy in primary teeth: new modalities for old rationales. Pediatr Dent 1994 Nov-Dec;16(6): 403-409.

3. International Agency for Research on Cancer, World Health Organization. Overall evaluation of carcinogenicity: an updating of IARC Monomorphs volumes 1 to 42. IARC Monogr Eval Carcinog Risks Hum (Suppl) 1987 Mar;7:1-440.

4. Clegg MS, Vertucci FJ, Walker C, Belanger M, Britto LR. The effect of exposure to irrigant solutions on apical dentin biofilms in vitro. J Endod 2006 Jun;32(5):434-437.
5. Hafez AA, Kopel HM, Cox CF. Pulpotomy reconsidered: application of an adhesive system to pulpotomized permanent primate pulps. Quintessence Int 2000 Sep;31(8):579-589.

6. Vargas KG, Packham B, Lowman D. Preliminary evaluation of sodium hypochlorite for pulpotomies in primary molars. Pediatr Dent 2006 Nov-Dec;28(6):511-517.

7. Vostatek SF, Kanellis MJ, Weber-Gasparoni K, Gregorsok RL. Sodium hypochlorite pulpotomies in primary teeth: a retrospective assessment. Pediatr Dent 2011 Jul-Aug;33(4):327-332.

8. Sweet CA. Procedure for treatment of exposed and pulp less deciduous teeth. J Am Dent Assoc 1930 Jun;17(6):1150-1153.

9. Redig DF. A comparison and evaluation of two formocresol pulpotomy technics utilizing "Buckley's" formocresol. J Dent Child 1968 Jan;35(1):22-30.

10. Doyle WA, McDonald RE, Mitchell DF. Formocresol versus calcium hydroxide in pulpotomy. ASDC J Dent Child 1962:29;86-97.

11. Myers DR, Shoaf HK, Dirksen TR, Pashley DH, Whitford GM, Reynolds KE. Distribution of 14C-formaldehyde after pulpotomy with formocresol. J Am Dent Assoc 1978 May;96(5): 805-813.

12. Pashley EL, Myers DR, Pashley DH, Whitford GM. Systemic distribution of 14C-formaldehyde from formocresol-treated pulpotomy sites. J Dent Res 1980 Mar;59(3):602-608.

13. Ranly DM. Assessment of the systemic distribution and toxicity of formaldehyde following pulpotomy treatment:part one. ASCD J Dent Child 1985;52:431-434

14. Gopikrishna, V. Grossman endodontic practice. 12th ed. New Delhi: Lippincott Williams and Wilkins; 2010. p. 342-360.

15. Rosenfeld EF, James GA, Burch BS. Vital pulp tissue response to sodium hypochlorite J Endod 1978;4:140-146

16. Kuo HY, Lin JR, Huang WH, Chiang ML. Clinical outcomes for primary molars treated by different types of pulpotomy: a retrospective cohort study. J Formos Med Assoc 2017 Mar; pii: S0929-6646(17):30078-30085. 